\title{
Measuring the economic impact of metrological frauds in trade metrology using an Input-Output Model
}

\author{
Bruno A. Rodrigues Filho ${ }^{1,2}$, Rodrigo F. Gonçalves ${ }^{2}$ \\ ${ }^{1}$ National Institute of Metrology, Quality and Technology - INMETRO, Duque de Caxias, \\ Brazil \\ ${ }^{2}$ Paulista University, São Paulo, Brazil \\ bafilho@inmetro.gov.br
}

\begin{abstract}
The present study aims to evaluate the economic distortion in trade metrology due to metrological frauds in measuring instruments used in the commerce and industry. The economic distortion represents the economic losses due to measurement deviations in trade. An Input-Output Model approach is carried out in order to determine the economic distortion whenever an output in a process represents the input to another one and it considers the aggregation of values of products traded in the economy. A case test is also conducted using empirical data of measurement errors and metrological frauds in the fuel sector in Brazil in order to determine their economic impact. The results show that the impact of metrological frauds increase the distortion uncertainty from US\$ $54,910,307.13$ to US\$ $303,734,309.35$ toward consumers' losses creating a great asymmetry in the market.
\end{abstract}

Keywords. Legal metrology, economic distortion, market asymmetry, Leontief.

\section{Introduction}

The commerce has always been present in the human history and it is not possible to imagine our society separately from it. Specifically, the commerce involving goods which values are based on weights and measures has always been present in people's everyday life. Initially, weights and measures were initially introduced to control food in trade [1] and the origins of the weighing instruments which are a symbol of parity, truth and justice date back to the oldest cultures 10,000 years ago [2].

The necessity for protection regards on the economic distortion or market asymmetry that is describe as the monetary value associated to a measurement deviation due to the inaccuracies intrinsic to the measuring processes as a consequence of errors, uncertainties, operator's inaccuracy, environmental conditions and others.

This economic distortion impacts both economy and society since deviations between buyers and sellers cause economic losses and unfair competition. Moreover consumer's protections aspects are also related to this market asymmetry that may be an indicator of the economic impact of legal metrology [3]. Several researchers have 
also presented the importance of legal metrology and its social and economical impact to the society, trade, industry and governments [4-8]. The initiative regarding using empirical data do evaluate the economic impact of inaccuracy of measuring instruments was initially proposed during the decade of 1970 [4] and several formulations using proxy variables have also been proposed, such as [5]: number of measurement related patents in comparison to the total; cost of certification as an indicator of industries willingness to pay for reliability; the sum of all industry equipment.

Despite the deviations of the measuring instruments regards to the measurement error theory, an intentional error or a metrological fraud caused by the operator in order to prejudice a buyer in a commercial transaction creates a great distortion in the economy. An example is the energy market in Germany, where the global competition has led to tighter profit margins increasing the risk for metrological frauds [6]. Recently, the global market has also been overflowed by metrological frauds in the fuel market occasioning severe losses to the buyers and competitors [7].

Regardless of the obvious aspect that a metrological fraud is prejudicial to the consumers and consequently the economy, its economic impact is not well known. The Input-Output Model allows to compute how a change in a product demand impacts its production contemplating the interconnections of productive processes since it considers that an output of a process can be an input to another one [8].

Consequently, the Input-Output Model, hereinafter called I-O for simplicity, permits to evaluate the economic impact a measurement deviation in a product to the economy, introducing a factor representing these deviations to the traditional Leontief's formulation, identifying how the deviations spreads across every sector on the economy.

Then, based on the I-O theory, the present study aims to evaluate the economical uncertainties cause by metrological frauds in trade. The measurement errors report for fuel disperses in the field in Brazil is used to provide an empirical case. In order to understand the impact of metrological frauds, we replaced a percentage of the empirical deviations by values based on known metrological frauds to evaluate the behavior of these frauds to the economy.

\section{Methodology}

\subsection{Formulation to compute the economic distortion}

The I-O formulation is based on the assumption that the productive processes are connected since an input of a process is the output of another process [8]. This interconnection is represented in a matrix system where the lines represent the outputs and columns the inputs. The basic conception is given by the product output $q$, which is represented by the final demand of products $F$ plus the intermediate consumption of industries $U$, as seen in (1).

$$
q=U+F
$$


Due to linear algebra, the basic formulation of the I-O is given by (2), where $g$ represents aggregation of $q$ in industry sectors, $I$ the identity, and $D$ and $B$ are coefficient matrices.

$$
g=(I-D \cdot B)^{-1} \cdot D \cdot F
$$

Consequently, the total national production of the $n$ aggregate products $g$ is given by the sum of the vector $g$, as shown in (2), where $g$ is given in monetary units.

$$
\boldsymbol{g}=\sum_{i=1}^{n} g_{i}
$$

To compute the impact of measurement deviation, a multiplier factor $\delta$ representing a percentage of deviation due to measurement errors is introduced in both intermediate consumption of industries and the final demand, as seen in (4).

$$
q^{\prime}=\delta . U+\delta . F
$$

Finally, the influence of the distortion due to measurement deviations, i.e. the economic distortion $E D$, is given by the difference of total production including $\delta, g^{\prime}$ less the total production of the $n$ aggregate products $g$, as shown in (3).

$$
E D=\sum_{i=1}^{n}\left(g_{i}^{\prime}-g_{i}\right)
$$

\subsection{Evaluating the impact of metrological frauds}

A metrological fraud can be understood as an intentional deviation introduced in a measuring instrument to promote financial gains to the seller over the buyer. The definition of measurement error is given in (6), where the error $\boldsymbol{e}$ is equal to the instrument value $e_{i}$ less the value of the standard used for comparison $e_{s}$.

$$
\boldsymbol{e}=e_{i}-e_{s}
$$

Consequently, positive values of $\boldsymbol{e}$ represent buyer' losses and negative values seller's losses. For example, in the fuel market, for a petro pump displaying 20.10/and the standard displaying $20.00 /$, and for $1 /=\$ 1.00$, it would represent a loss of $\$ 0.10$ for the buyer.

Since the measurement deviations of instruments can be represented by an average and measurement uncertainty regarding a statistical distribution, the economy distortion must also contain an uncertainty. For the present study it is reasonable to assume that measurement errors of the instruments used in the market and industry follow a gauss distribution. We also assumed the standard deviation to represent the measurement uncertainty in the present study.

However, the set of illegal devices would follow a different statistical distribution once they are intentionally regulated to provide higher positive measurement errors. Thus, the contributions of fraudulent devices contribute only to positive values of deviations. So in order to analyze the contributions of errors to the economic distortion uncertainty, we considered the mutual distribution uncertainty to positive values 
(buyer's losses) and the regular devices distribution to negative values (seller's losses), as seen in figure 1 .

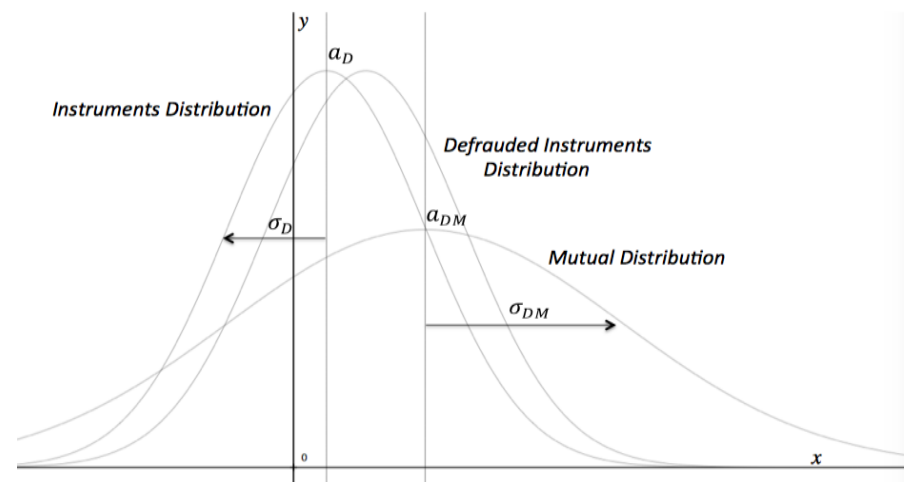

Fig. 1. Uncertainty evaluation for the economic distortion.

A mutual distribution uncertainty $\sigma_{D M}$ is obtained combining deviations of both fraudulent and regular measurement instruments distributions. The measurement uncertainty is represented in (7), where $a_{D M}$ represents the average of the mutual distribution, $a_{D}$ the average and $\sigma_{D}$ the standard deviation of the instruments distribution.

$$
\sigma_{D}-a_{D} \leq \text { measurement uncertainty } \leq a_{D M}+\sigma_{D M}
$$

\subsection{Simulating a metrological fraud}

In order to evaluate the economic impact of metrological fraud we used an empirical database of measurement errors for automotive ethanol dispensers in Brazil [9]. And, the metrological frauds for the fuel market usually varies from $6 \%$ to $12 \%$ [7].

To analyze how the economic distortion behaves when fraudulent instruments are used in the commerce, we have established two variables: the percentage of fraudulent devices and the measurement error due to the fraud. Then, a Scilab 5.5.2 algorithm replaces randomly a percentage of instruments in the database by fraudulent values, as follow:

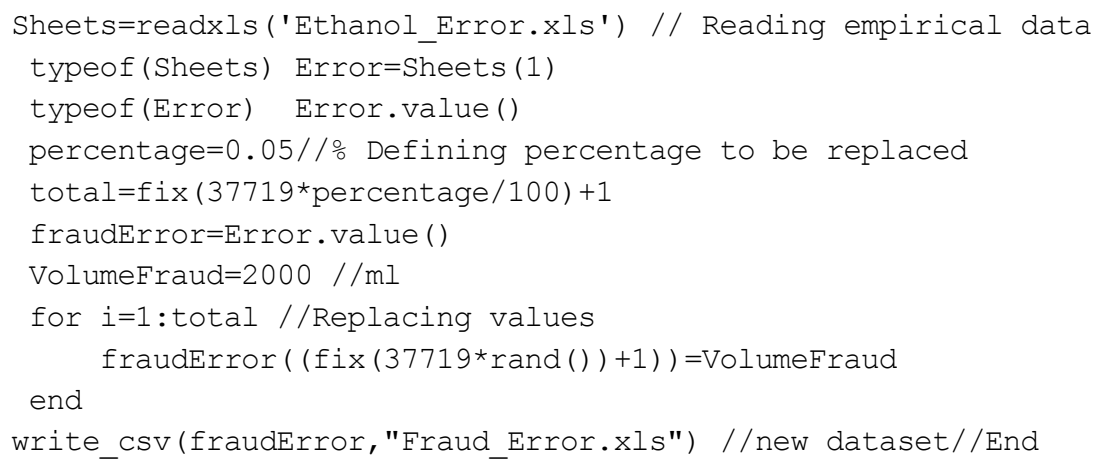


Figure 2 also illustrates the process of simulating fraudulent instruments in the market.
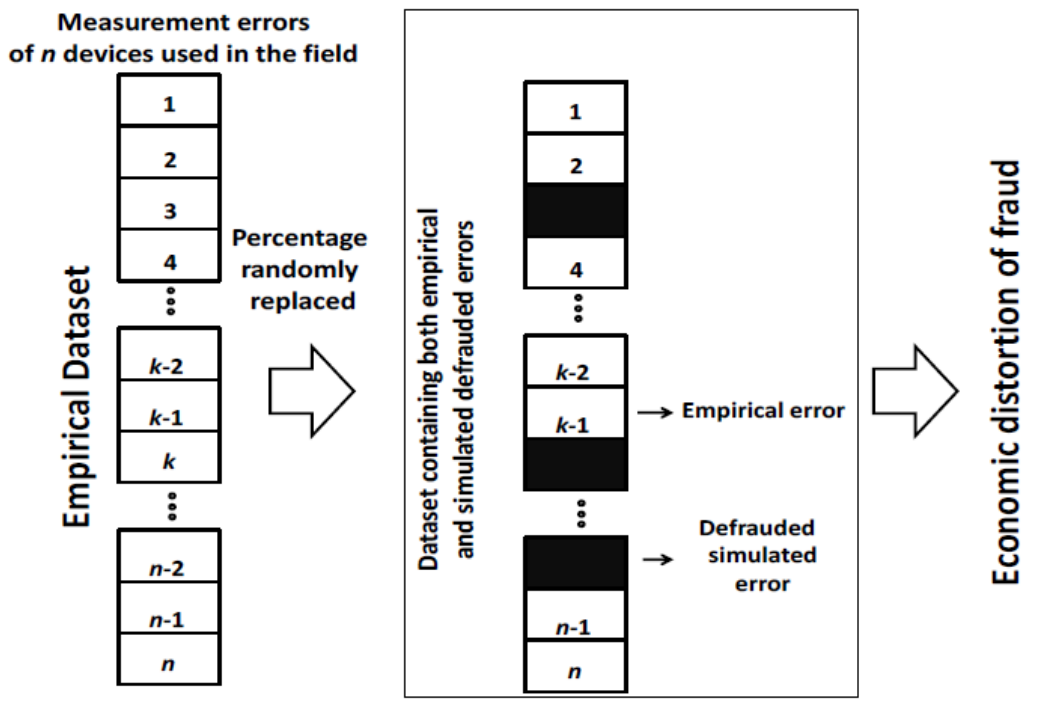

Fig. 2. Process for replacing empirical measurement errors for simulated defrauded values.

The empirical data of measurement errors of automotive ethanol dispersers where the average $\left(a_{D}\right)$ and the standard deviation $\left(\sigma_{D}\right)$ comprising 37,719 ethanol dispensers verified in 2014 are represented in ml units by: $a_{D}=4.22 ; \sigma_{D}=40.83$. The great divergence of these dispensers is mainly caused by the imprecisions of the measurement of fuel, such as environmental conditions, humidity, user's proficiency and others [10].

Finally, to compute the economic distortion according to 5, we used the latest published Brazilian Input-Output matrices representing the economy in 2005 [11] as well as the dollar exchange rate [12]: US\$ $1.0000=\mathrm{R} \$ 2.3407$.

\section{$3 \quad$ Results}

For a bigger percentage of fraudulent devices used in trade, the economic distortion associated to the measurement errors is consequently bigger. Table 1 shows the results of economic distortion from a range of $0.01 \%$ to $1 \%$ of fraudulent measuring instruments introduced in the commerce comparing to a scenario where no frauds are used. A fraud value of $10 \%$ is applied to the results presented in table 1 , representing a deviation of $2 /$ for each $20 /$ traded.

The measurement uncertainty regarding seller's losses remains constant once a fraud affects only the buyers. The average representing the economic distortion is linear dependent of the percentage of fraudulent devices $\left(R^{2}=0.9998\right)$. 
Table 1. The variation of the measurement uncertainty according to the percentage of fraudulent devices for a $10 \%$ volume deviation.

\begin{tabular}{c|cccc}
\hline \multirow{2}{*}{$\begin{array}{c}\text { \% of fraudulent } \\
\text { instruments in } \\
\text { the market }\end{array}$} & $\begin{array}{c}\text { Economic } \\
\text { Distortion } \\
\text { Average (US\$) }\end{array}$ & \multicolumn{2}{c}{ Measurement Uncertainty } & \\
\cline { 3 - 4 } & Buyer loss & Seller loss & Range (Buyer + Seller) \\
0 & $\$ 5,673,853.89$ & $\$ 54,910,307.13$ & & $\$ 104,146,760.38$ \\
0.01 & $\$ 5,969,647.42$ & $\$ 67,441,271.42$ & & $\$ 116,677,724.66$ \\
0.05 & $\$ 7,018,370.10$ & $\$ 88,496,693.13$ & $\$ 49,236,453.24$ & $\$ 137,733,146.37$ \\
0.1 & $\$ 7,018,370.10$ & $\$ 109,686,654.24$ & & $\$ 158,923,107.49$ \\
0.5 & $\$ 19,119,034.64$ & $\$ 216,363,722.30$ & & $\$ 265,600,175.55$ \\
1 & $\$ 32,295,351.86$ & $\$ 303,734,309.35$ & & $\$ 352,970,762.60$ \\
\hline
\end{tabular}

Figure 3 shows the economic distortion variation due to metrological frauds, displaying the measurement uncertainty. It is also possible to observe the great divergence between consumer and seller's losses.

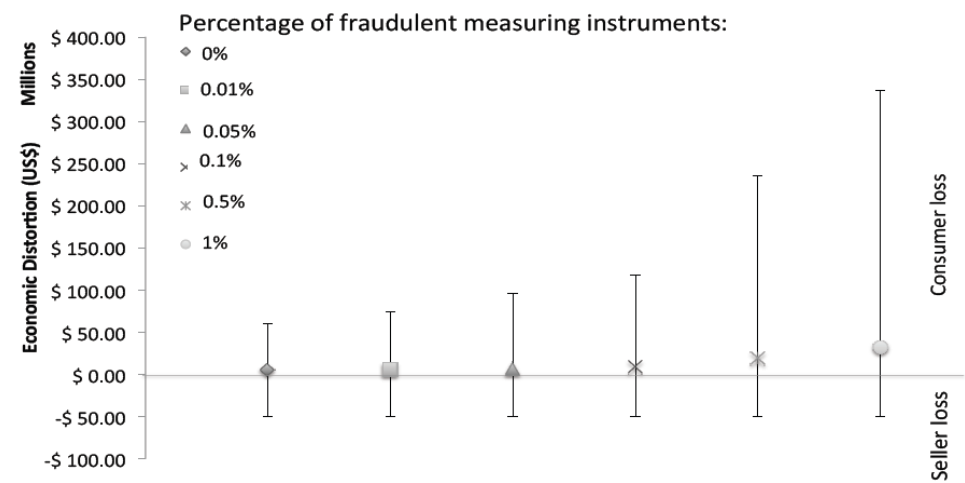

Fig. 3. Effect of metrological frauds on the economy according to the percentage of fraudulent instruments.

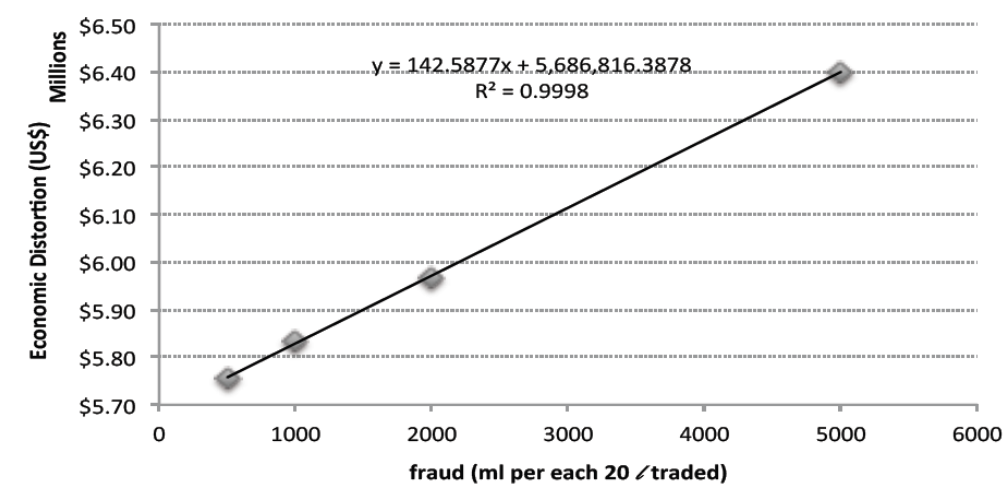

Fig. 4. Economic distortion for a constant number of fraudulent devices and volume variation. 
The economic distortion for bigger percentage values of fraudulent instruments in the market introduces bigger consumers' losses differently when comparing to the sellers' losses, which remains constant. As a direct consequence, the probability of consumers' losses is bigger than sellers' and it indicates a component of unfair competition caused by the asymmetry of information. The range of US $\$ 352,970,762.60$ uncertainty caused by $1 \%$ of irregular instruments in the commerce is more than three times bigger than the range of uncertainty if no fraudulent instruments were used and the uncertainty toward consumer's losses is six times bigger than the initial uncertainty, where no fraud is applied to the market.

In order to identify the behavior of the economic distortion due to the volume fraud dispensed to the consumers, we simulated the economic distortion for a constant number of fraudulent instruments and ranged the value of fraud, from $500 \mathrm{~m} /$ to 5000 $\mathrm{m} /$ for each $20 /$ traded. Figure 4 shows the behavior of the economic distortion for different values of fraud when keeping the percentage of $0.01 \%$ fraudulent instruments in the market constant.

The economic distortion introduced in the economy increases the consumers' losses in the trade due to bigger errors of volume dispensed. The dependence between the economic distortion and the fraudulent measurement values is linear, for $R^{2}=0.9998$.

\section{Conclusion}

The Input-Output Model allowed us to compute the economic distortion due to the measurement errors of instruments used in trade contemplating the interconnections of the sector on the economy. Since a fraud is intentionally introduced in the market it changes the random behavior of deviations and add a systematic deviation component, which reflects in the economic impact to the economy.

The methodology proposed to compute the impact of fraudulent devices in the market also permitted to identify their impact on the economy based on two variables: the percentage error of measurement traded and percentage of fraudulent instruments.

Empirical information of the fuel market in Brazil also enable to evaluate the impact of metrological frauds showed to be expressive and it increases the range of uncertainty of the economic distortion from US\$104,146,760.38 to US\$ 352,970,762.60 toward consumers' losses, for $1 \%$ of fraudulent devices for a $10 \%$ deviation. The uncertainty representing buyer's losses increases from US\$ 54,910,307.13 to \$ $303,734,309.35$ creating a big asymmetry between buyers and sellers in the market. Moreover, we identified that the economic loss is linearly dependent of the volume deviation introduced in the instrument, for a constant number of fraudulent devices.

The big impact of metrological frauds in the commerce may affect the relation between buyer and seller due to the great asymmetry of information caused by the intentional deviation in the measurements, creating unfair competition that may also impact honest sellers leading the economy to a failure.

Additionally, the proposed model can also be applied to any industry's quality management system in order to evaluate the losses due to the measurement processes since the I-O analysis is a consolidate model in economy. 


\section{Acknowledgement}

The authors acknowledge the support of INMETRO, which enabled us to carry out this research.

\section{References}

1. Birch, J.: The Expanding Scope of Legal Metrology and The Changing Role of The State in A Globalised World. OIML Bull. XLV, 23-24 (2004).

2. EULER, W., Hennef, Sieg, M.: History of Scales Part 15: Automatic Gravimetric Filling Instruments (Agfis) - Weighing and Bag Filling Machines for Loose Bulk Products. OIML Bull. 4, 8-9 (2015).

3. Rodrigues Filho, B.A., Gonçalves, R.F.: Legal Metrology, The Economy and Society: A Systematic Literature Review. Measurement. 69, 155-163 (2015).

4. Stiefel, S.W.: Management Assistance for Weights and Measures Progress, Measuring Inaccuracy's Economic Distortion. Presented at the 58th National Conference on Weights an Measures (1973).

5. Birch, J.: Benefit of Legal Metrology for The Economy and Society - A Study for The International Committee of Legal Metrology. International Organization of Legal Metrology - OIML, Paris, France (2003).

6. Kochsiek, M., Schulz, W.: Modernization of Legal Metrology in Germany. OIML Bull. XLV, 27 - 31 (2004).

7. Leitão, F.O., Vasconcellos, M.T., Brandão, P.C.R.: Contramedidas De Hardware Y Software Sobre El Fraude De Alta Tecnología Al Surtidor De Combustible Bajo El Alcance De Metrología Legal. In: 9th International Symposium "Metrologia 2014” Proceedings. p. 8. , Havana, Cuba (2014).

8. Leontief, W.: Structure of The World Economy: Outline of A Simple Input-Output Formulation. Proc. IEEE. 63, 345-351 (1975).

9. Rodrigues Filho, B.A., Soratto, A.N., Gonçalves, R.F.: Information Systems as A Tool to Improve Legal Metrology Activities. In: 8th Brazilian Congress on Metrology Proceedings. , Bento Gonçalves, RS, Brazil (2015).

10. Batista, E., Almeida, A., Almeida, N., Reis, C., Filipe, E.: Comparison on The Verification of Fuel Dispensers. OIML Bull. LIV, 19 - 24 (2013).

11. IBGE. , Rio de Janeiro, Brazil (2008).

12. Brazilian Central Bank,

http://www4.bcb.gov.br/pec/taxas/port/ptaxnpesq.asp?id=txcot acao. 